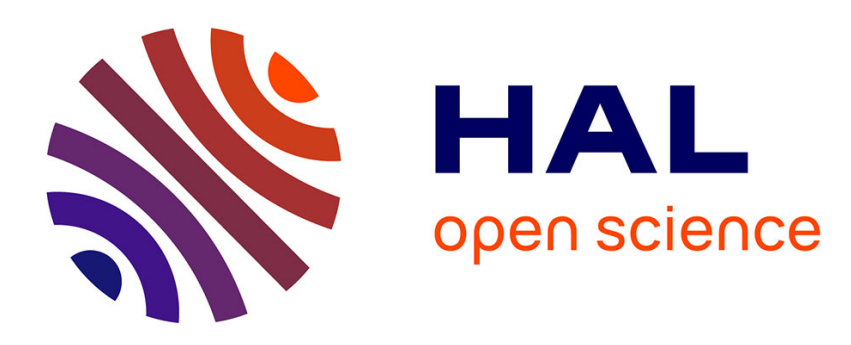

\title{
Reading Literature and the Political Ecology of Gestures in the Age of Semiocapitalism
}

\author{
Yves Citton
}

\section{To cite this version:}

Yves Citton. Reading Literature and the Political Ecology of Gestures in the Age of Semiocapitalism. New Literary History, 2013, 44 (2), pp.285-308. 10.1353/nlh.2013.0013 . hal-01373214

\section{HAL Id: hal-01373214 \\ https://hal.science/hal-01373214}

Submitted on 30 Sep 2016

HAL is a multi-disciplinary open access archive for the deposit and dissemination of scientific research documents, whether they are published or not. The documents may come from teaching and research institutions in France or abroad, or from public or private research centers.
L'archive ouverte pluridisciplinaire HAL, est destinée au dépôt et à la diffusion de documents scientifiques de niveau recherche, publiés ou non, émanant des établissements d'enseignement et de recherche français ou étrangers, des laboratoires publics ou privés. 


\section{Reading Literature and the Political Ecology of Gestures in the Age of Semiocapitalism}

\section{Yves Citton}

Gestures are central to our aesthetic experiences. This is not only true of choreography, theater and music, but of literature as well. In the following pages, I will (somewhat presumptuously) attempt to reframe our perception of the last three hundred years of literary history by considering the experience of reading literature as a form of gestural impregnation. Within the broad context of what is now frequently referred to as "media archeology", reading tales, short stories, novels or plays appears as a complex form of immersion in fictional universes, leading the immersed subject to develop specific relational gestures - in a very similar manner to the way in which a Wii player is led to execute certain bodily gestures when interacting with the machine.

I will first suggest that the type of relational gestures inculcated through literature over the past centuries should be analyzed in close connection with the development of political economy. I will then attempt to show how literary studies, as well as the humanities at large, deserve to be reframed in order to accommodate the softness of interpretive gestures against the hardness of machine protocols. In a brief last section, I will sketch some of the ways in which literary interpretation can inspire claims for new human rights within a broad political ecology of gestures.

Because my argument is (ridiculously) wide and far-reaching, I will only be able to sketch it within the limits of this article-hence its rather dogmatic style, which will assert a series of quasi-dogmatic theses. In an issue devoted to the theme of reading, I will leave it to the reader to connect the dots-hoping that the resulting figure will be more convincing than the skeleton presented here only in its most massive features ${ }^{1}$.

\section{Fictional Immersion: from Affection to the Inculcation of Gestures}

I. To read is to expose oneself to being affected. The development of new media helps us reconsider the activity of reading within a new set of analogies and models. While, at least since Cervantes' Don Quixote, it has been often stated that the reader of a novel could be absorbed in the fictional world depicted in it; while, at least since the middle of the $18^{\text {th }}$ century, as Michael Fried has showed, the theatrical apparatus has been explicitly orchestrated

\footnotetext{
1 This article condenses and develops several sections of my latest book, entitled Gestes d'humanités. Anthropologie sauvage de nos expériences esthétiques (Paris: Armand Colin, 2012).
} 
around effects of absorption ${ }^{2}$, the explosion of new and ever more powerful technological means of production of virtual reality over the last decades can be read in close parallel with a renewed theoretical interest in the processes of simulation and fictional immersion ${ }^{3}$. Reading a short story or a novel used to present strong analogies with seeing a play or watching a movie: the reader enters a different "virtual" world, separated in space and time from her actual reality; she does her best to disconnect her senses from what is close to her (a coughing neighbor, a worry about a sick relative) in order to project herself into another world sketched by the sentences read on the page, which conduct her imagination into "seeing" the unfolding of the plot, as she could see the story staged in a theater or projected on a screen.

This cinematic model already included emotional reaction on the part of the reader/viewer. We are told that the first spectators of the Lumière Brothers' Train arriving in La Ciotat's Station (1896) feared they would be crushed by the approaching locomotive and fled in a panic. True or legendary, this reaction illustrates the obvious fact that readers and viewers are necessarily affected by what they perceive, even if the specific nature of this affection obviously varies from medium to medium, from genre to genre, from book to book. Outwardly, we are led to laugh, or smile, or cry, while watching a movie or reading a fiction; inwardly, each twist of the plot, each choice of picture or word elicits a certain reaction of joy or sadness, depending on the way in which we are led to situate ourselves within the narrative world.

The complex but enlightening (even if somewhat trendy ${ }^{4}$ ) definition of the affect elaborated by Spinoza in his Ethics (1677) helps us understand one crucial feature of such a fictional immersion: the affects are always double-sided. My passions, emotions, feelings, sentiments (all possible translations for the Latin affectus) can be simultaneously seen as what is (passively) imprinted in me by my relations to my environment ( $\mathrm{I}$ am blinded by the sun in my face, I am irritated by my boss' remark, I am aroused by a seductive look), and as what I do in (active) reaction to such affections (closing my eyes, quitting my job, approaching the charming person). In Spinozese: an affect is both a sensory affectio, (necessarily) imposed on the individual by his or her relation to the environment, and a (no less necessary) variation in his or her agency (potentia agendi). In other words: one cannot be (emotionally) affected by what one reads without being made to react to it in a certain manner. The fact that this necessary reaction can be trained to evolve, according to the type of associations the individual's imagination tends to make between images and emotions, provides the backbone for a Spinozist ethics, conceived as an effort to "re-concatenate" our affections.

Devices like the Wii offer a caricature of the principle that affection and agency are two sides of the same coin. The truth of the activity of reading, of course, is a lot more

\footnotetext{
${ }^{2}$ See Michael Fried, Absorption and Theatricality. Painting and Beholder in the Age of Diderot (Chicago: University of Chicago Press, 1988).

${ }^{3}$ See for instance, from very different points of view, Jean Baudrillard, Simulacra and Simulation (Ann Arbor: University of Michigan Press, 1995); Jean-Marie Schaeffer, Why Fiction? (Lincoln: University of Nebraska Press, 2010); Marie-Laure Ryan, Narrative as Virtual Reality. Immersion and Interactivity in Literature and Electronic Media (Baltimore: Johns Hopkins University Press, 2001); Oliver Grau, Virtual Art. From Illusion to Immersion (Cambridge, MA: MIT Press, 2003).

${ }^{4}$ See Antonio Damasio, Looking for Spinoza: Joy, Sorrow, and the Feeling Brain (New York: Mariner Books, 2003). For more developments on an "economy of affects", see Yves Citton, "Esquisse d'une économie politique des affects" in Yves Citton and Frédéric Lordon, Spinoza et les sciences sociales : de la puissance de la multitude à l'économie des affects (Paris : Éditions Amsterdam, 2008), 45-123.
} 
complicated. We are not Don Quixote, nor do we run out of movie theaters when a train enters a station in a film. Until recently, the aesthetic experience involving fiction-contained within an atopian space of "willing suspension of disbelief" - was described as involving an inhibition of our bodily reactions to the fictional events. It was characteristic of ridiculous Quixotic figures ("peasants" or "savages" discovering theater for the first time) to attempt to intervene (physically) in the story displayed on stage, or to write to the publisher and offer their help to an imaginary character.

II. To read modern literature is to be trained in developing relational gestures. Immersion in digitally-produced virtual reality, anticipated by certain devices like the Cinemascope, the Imax, or movies in 3D, gave us a fresh look on the matter. My body can feel vertigo in an Imax theater, and interactive games expect me to react physically to a simulation. What is suspense, however, if not a nervous (i.e., physical) tension affecting my body as a result of my reading a story? When I "feel good" (or bad) about a fictional act, when I experience sympathy for a character, my identification with him leads me to mimic the relational gestures performed within the fictional world.

By "relational gestures", I mean mental attitudes 1) caused by the perception of certain social relations within a certain social situation (on the side of the affectio), and 2) pushing the observer towards certain forms of intervention in this situation (on the side of the potentia agendi). While the active intervention is obviously inhibited in the case of fictional narratives, the affects are nevertheless (more or less fully) experienced by the reading subject. When Augustus "forgives" Cinna in Corneille's tragedy, when Henri Meyer shows his "care" for a young seamstress in Isabelle de Charrière's Letters written from Neuchâtel, when a rake "seduces" his victim in a libertine novel, they all perform certain relational gestures which trigger in the reader powerful affective reactions (of relief, frustration, disgust, suspicion, etc.).

Even if, as we will soon see, reading cannot be reduced to psychological identification, it would be unrealistic to disqualify such reactions, which are part and parcel of our narrative experience. Reading a novel, watching a play or a movie pushes us not only to mimic, but to experience certain relational gestures "from the inside" of the character's mind, as it were. That such an experience, repeated dozens, hundreds or thousands of times, tends to build certain habits in the reader-viewer seems rather obvious: we learn to act (in real life) by experiencing relational gestures in narrative immersion. Over the last 300 years, as reading became accessible to ever larger segments of our populations, and, later, as audio-visual entertainment spread among all social classes, narratives have trained us to be the ethical agents we have become.

\section{The Political Economy of Immersive Gestures}

III. The modern novel has been a near-perfect companion to the shaping of homo oeconomicus. It has become a commonplace within the humanities to consider literature as a form of resistance to the hegemony of economics over the development of Western 
modernity ${ }^{5}$. While a good case can be made for such an argument, I would like to sketch an alternative view, which stresses the ambivalence of the relation between literature and economics (aka, Capitalism).

Although literature professors often enjoy considering themselves as free-thinkers, subversive agents and intellectual rebels, literature as a discipline and as an institution - at least in France - has most of the time sided with power and social domination. Either because they were inflicted upon students by zealous teachers in the name of a superior canon (under the threat of bad grades and social stigma), or because they were duly aligned with the dominant ideologies of the times, most successful and widely-read novels of the nineteenth and twentieth century have trained their readers into being "good working men and women" rather than rebellious souls. The fact that yesterday's rebel comes to be worshiped within today's canon tends to twist our perception: at each given period, readers have been inculcated into socializing gestures, rather than subversive ones. If the relational gestures experienced in novels do indeed train us to develop certain habits, then novels are to be counted among the main culprits for the production of the modern homo oeconomicus.

A quick survey of the remarkably parallel developments of political economy and the novel, considered here mostly from within the French tradition, should suffice to raise our suspicion. The modern novel emerged (with Lesage, Marivaux, Prévost or Richardson) at the same time when the groundwork for political economy was laid down by Boisguilbert, Melon, Cantillon, Quesnay, Turgot and Adam Smith ${ }^{6}$. Both parallel traditions staged individuals motivated by what Bruno Latour recently called "passionate interests", collapsing the distinction suggested earlier by Albert Hirschman's classical study The Passions and the Interests $^{7}$. Classical political economy attempted to explain, map, model and ultimately control the outward behavior of agents whose tormented affects were analyzed and scrutinized by the narrators of romans-mémoires. When contemporary critics made fun of the novelists' lengthy and pretentious subtlety in dissecting the most minute and insignificant change of mind of their characters, they did not understand what was at stake in this literary genre, inherited from the previous decades (just as political economy itself has been presented as a direct heir to a Jansenist disillusioned vision of $\operatorname{man}^{8}$ ): from Marivaux to Stendhal, through Rousseau and Goethe, the novel simultaneously analyzed, categorized, colonized, and shaped our relational gestures. By immersing the readers in situations described in such a way that they could identify with the conundrums and dilemmas experienced by the main characters, such narratives progressively trained ever wider segments of our populations simultaneously to feel (fictional) passions and to take enough distance towards them, in order to measure their consequences within a calculation of their best interests (and moral attachments).

\footnotetext{
5 See for instance Martha Nussbaum, Not For Profit: Why Democracy Needs the Humanities (Princeton University Press, 2010).

${ }^{6}$ For a literary reading of the emergence of political economy in the $18^{\text {th }}$ century, see Yves Citton, Portrait de l'économiste en physiocrate. Critique littéraire de l'économie politique (Paris: L’Harmattan, 2001).

7 Albert Hirschman, The Passions and the Interests. Political Arguments for Capitalism Before its Triumph (Princeton University Press, 1977); Bruno Latour and Vincent-Antonin Lépinay, L'économie, science des intérêts passionnés. Introduction à l'anthropologie économique de Gabriel Tarde (Paris: La Découverte, 2008); Bruno Latour, An Inquiry Into Modes of Existence (Cambridge, MA : Harvard University Press, 2013).

${ }^{8}$ See Jean-Claude Perrot, Une Histoire intellectuelle de l'économie politique (17e-18e siècle) (Paris: Editions de l'Ecole Pratique des Hautes Etudes en Sciences Sociales, 1992).
} 
Towards the end of the nineteenth century, as political economy was taking its neoclassical marginalist turn (focusing on differentials of intensities located on borderline situations), the novel too was led to abandon its previous double vision (subjective affects perceived within larger fields of aggregated interests), in order to investigate self-absorbed affections increasingly shut off from, or disillusioned with, the resources of instrumental rationality. From Huysmans to Blanchot, through Proust, Svevo and Joyce, the novel went through its own marginalist revolution, replacing a claim to decipher the true value of things and behaviors with a more modest attempt to register the differentials of intensities experienced by disoriented subjectivities.

As for the formalist turn which took over (French) literature from the 1950s on, it would be tempting to set it against the background of the exacerbated formalization of an economic science increasingly running on mathematic models, ready to be plugged into algorithmic cybernetics. From the Nouveau Roman experiments to the Oulipo and the radical aesthetics of Tel Quel, soon echoed by the structuralist grip on literary criticism, the novel became (briefly) obsessed with numbers, pseudo-scientific formulas, and systematic distributions (rather than the production, dissection, or evaluation of affects).

Of course, the actual audience of such avant-gardist experiments was extremely limited, and it would be ludicrous to claim that they "shaped" in any way the homo oeconomicus of the late twentieth century. For, under the surface of these three long phases of parallel unfolding of our economic and novelistic discourses, a deeper and more important dynamic relation was at work on the articulation zones where affects and gestures meet narratives and social control.

IV. Thanks to their critical and adaptive dimensions, literary (and, later, cinematic) immersive gestures have provided the challenges and resources which allowed semiocapitalism to colonize most of our life forms. Political economy was not merely a matter of discourse. It accompanied an unprecedented process of industrialization, which is still restructuring the lives of billions of humans on the Asian continent, and which can be broadly characterized by five correlated features: 1) automation of physical gestures delegated to machines; 2) residual need for limited human intervention through impoverished and unskilled gestures on the factory line; 3) top-down organization of labor; 4) unprecedented profits generated mostly by economies of scale; 5) basic learning and skills transmitted through explicit rules and protocols.

The development, analysis, classification, inculcation of relational gestures provided through fictional immersion and aesthetic experiences over the past three hundred years should be understood against this general background. For, of course, reading a novel, even the worst type of tear-jerker, involves much more than mere immersion through naïve identification with the protagonist. Readers are not only aware of the simulated nature of fictional situations; by knowing they are dealing with signs rather than with real life, they entertain an inherently distanced and potentially critical relation to the affective gestures they may be led to simulate.

Thanks to this reflective and critical posture, while readers are simultaneously immersed in some form of virtual reality, reading literature directly counter-effects the five features of industrialization mentioned above: 1) by its massive mobilization of affects and (sexual) desires, narratives relocate the source of movement in humans rather than machines; 2) by 
exploring the difficulties and problems raised in inter-human relations, they lead to the identification, imitation, and massive inculcation of ever more complex relational gestures, involving an increasingly large number of agents; 3) by throwing us in the middle of a difficult situation, they force us to elaborate bottom-up or horizontal (rather than top-down) responses to problems of coordinating actions among humans; 4) by immersing us in a particular (and always different) knot of relations, they foster the invention of singular solutions, crafted on a case by case basis (against the homogenizing logic of economies of scale); 5) by staging complex reactions to which we are led to identify, they transmit skills by the virtue of imitation and exemplarity, which is the most efficient way to communicate gestures (rather than through explicit commands and protocols).

The inculcation of relational gestures - through literature, and later films and TV series - can thus be seen as the other (necessary and complementary) side of industrialization. Modernization (capitalism) needed entertainment (spectacle) to nurture desires, adaptive and relational skills, in its collaborators/consumers. Aesthetic experiences provided the field of experimentation, invention, adjustment, dissemination necessary for the elaboration of the social gestures on which productive collaboration depends.

As capitalism, in its richest countries, moved from its industrial form towards an economy of services, communication and entertainment, more and more feedback loops could be observed between the signs used as means of production and the signs used to mobilize the desires of the collaborating/consuming populations - leading to what Guy Debord called "the society of the spectacle", Jean Baudrillard "full screen" (écran total, aka "hyperreality"), or, more recently, Franco 'Bifo' Berardi "semiocapitalism." By emphasizing the role of signs in the circulation of wealth, power and desires, this latter label is the most appropriate for my overall argument ${ }^{\underline{9}}$. It suggests that what was described earlier in terms of affects should always also be approached in terms of signs. This helps us to understand the complementarity between widely disseminated "traditional" (immersive) types of narratives, calling for the reader to identify with the characters, and "avant-garde" formalist experiments, toying with self-reflective awareness and self-critical postures.

For immersive and critical gestures, far from being incompatible, are rather to be seen as reversely proportional components of our relations to any narrative. Reading novels, whatever their genre, refinement or popularity, remains first and foremost an exposure to, and management of, signs. The complex moves by which we react to the phrases read on the page are inseparably affective and intellectual, narrative and aesthetic: as Marielle Macé has eloquently shown, the reading experience "conducts our conduct" on the two superimposed levels of stylistic orientation, within the sentence, and of existential orientation, within our life forms: "we need to consider reading as a form of conduct, or behavior, rather than as a form of deciphering. A conduct "within" the books: a matter of attention, perception, experience, a mental, physical and affective wayfaring within language forms. But also a conduct "with" the books, and even a conduct "by" the books, as our life finds guidance in them: a matter of interpretation, use, application of what we read into what we do in our individual lives."10

\footnotetext{
${ }^{9}$ Franco 'Bifo' Berardi, Precarious Rhapsody. Semiocapitalism and the pathologies of the post-alpha generation (London: Minor Composition, 2009).

${ }^{10}$ Marielle Macé, Façons de lire, manières d'être (Paris: Gallimard, 2011), 15. (My translation)
} 
My insistence on putting the notion of gesture at the core of our aesthetic experiences is motivated by the inherently semiotic nature of gestures: while we may (foolishly) believe that an agent executes an act as a result of some spontaneous and self-sufficient urge, we all know that a gesture is something made to be performed under the gaze of an actual or potential audience. Gestures are what our social fabric is made of, more than ever before in the age of semiocapitalism and its "cinematic mode of production"11.

The more active the reader (as described by theorists of reader-response criticism), the more reflective she is towards the signs that mediate the potentially immersive experience, the more dynamism her reading will bring into the echoing chamber of gestures generated by and around a narrative. In its ceaseless need for competitive reconfigurations, semiocapitalism needs all of us to be virtuosi in juggling with our various masks, faces, and profiles, moving as fluidly as possible in and out of the many contradictory social roles we are led to play. Through the immersive and critical gestures they have triggered in their readers and viewers, novels, plays, films, and television series have been the gym halls in which, over the last three hundred years, we have practiced the moves that now allow us to survive the multifarious schizophrenias semiocapitalism imposes upon us.

\section{The Humanities as Reflective Practices of Interpretive Gestures}

\section{The widening and intensifying domination of automated protocols, generated by} semiocapitalism over our most vital moves, calls for making human gestures a primary frontier of resistance. In the wake of André Leroi-Gourhan's influential book Le Geste et la parole (1964) ${ }^{12}$, a common evolutionary narrative widespread among anthropologists has portrayed modernization and industrialization as leading to a progressive atrophy of our gestural skills. Craftsmen of the past inherited complex, subtle, and refined bodily gestures necessary to weave a basket, to sculpt clay, or to carve wood through a patient social training based on imitation, trial, and error ${ }^{13}$. As our productive forces were dramatically increased with the advent of the needle factory celebrated by Adam Smith, the bodily gestures accomplished by each individual worker suffered from a no less dramatic impoverishment, being reduced to repetitive and mechanical moves dictated by the assembly line, as emblematically depicted in Charlie Chaplin's Modern Times. As machines have taken over the production of our chairs, tables, pots, and pans, the human hand tends to lose its inherited skills - as currently witnessed by those of us who find it increasingly hard to write (legible sentences) by hand, due to the ubiquitous presence of keyboards, tablets, and printers.

Leroi-Gourhan's main insight, contemporary to Marshall McLuhan's, led many to consider computerization (still at its early stage in 1964) as the next logical step in the same process of externalizng sequences of operations (chaînes opératoires) previously embodied

\footnotetext{
${ }^{11}$ Jonathan Beller, The Cinematic Mode of Production. Attention Economy and the Society of the Spectacle (Hanover: Dartmouth University Press, 2006).

12 André Leroi-Gourhan, Gesture and Speech (Cambridge: MIT Press, 1993).

13 For a recent reflection on such issues, see Tim Ingold, The Perception of the Environment. Essays on Livelihood, Dwelling and Skill (London: Routledge, 2000) and Being Alive. Essays on Movement, Knowledge and Description (London: Routledge, 2011).
} 
within individual skills. As the assembly line externalized our bodily gestures, the computer externalizes our mental operations, leading humans to be progressively expropriated from their individual body and brain. This evolution, which started with our physical skills and later extended to basic mental tasks like calculus, computation, chess, or word processing, is now extending to our relational gestures: the whole field identified as "algorithmic governance" deals with the way each individual deals with his or her social environment. When amazon.com suggests a new book I should be interested in (taking over the relational gestures previously performed by my neighborhood bookseller), when surveillance systems flash my internet connections and email exchanges as corresponding to a potential "terrorist" profile (taking over the job previously performed by a secret service agent), when automated trading invests and divests millions of dollars in a matter of milliseconds (taking over the intuitive but slower judgment of a human trader), or when, some day in a post-human future, my electronic messaging service sends customized responses to most of the hundreds of emails flowing daily into my in-box (as post-humanist guru Ray Kurzweil promises will happen within a few years ${ }^{14}$ ) — in all such cases our relational gestures, patiently inculcated by three centuries of novels, theater, films, and television series, are externalized, threatening to leave our mental and relational skills as dramatically atrophied as our bodily capacities.

As demonstrated by the daily madness of automated trading, semiocapitalism thrives on the accelerating circulation of signs, with little regard to the way in which these signs are lived (or not) by actual subjectivities. As Friedrich Kittler noted in a famous article, software and hardware are so intimately intertwined that it is virtually impossible to maintain a clearcut distinction between the two ${ }^{15}$ : the chains of signs and symbols comprised within a computer program "write ahead" (pro-grammein) our behavior as mechanically as the machine commands the worker's gestures on the assembly line. Alexander Galloway has demonstrated how, in our supposedly decentralized world made of social networks and "freely" chosen connections, power and control exist through the "protocols" which pre-write our interactions ${ }^{16}$. Software and computing machines are only the latest avatars of a much longer evolution, started many centuries ago with the development of state bureaucracy, which was for a long time the first and main source of imposed protocols (military, judicial, fiscal). All such protocols have in common pre-set parameters which rigidly condition the forms of human interactions. Even when their stated goal is to be open to any type of content, as it is the case on the world wide web, they constrain and mechanically pro-gram our relational gestures in order to foster their communicability.

Computerized protocols mark a new stage in the development of semiocapitalism for at least two reasons. Their potentially oppressive power of control rests on the difference between what Félix Guattari (inelegantly but accurately) called "signifying" vs. "a-signifying" semiotics. As Maurizio Lazzarato has shown, our dominant Foucaldian tradition has taught us to identify "power" with institutions relying on "signifying semiotics" to induce various processes of subjectivation: these institutions (schools, legal courts, social services, market competition) call on humans to behave as individual subjects by sending signs addressed to

\footnotetext{
${ }^{14}$ Ray Kurzweil, The Singularity Is Near: When Humans Transcend Biology (New York: Penguin, 2005).

${ }^{15}$ Friedrich Kittler, "There Is No Software" (ctheory website, 1995, http://www.ctheory.net/articles.aspx?id=74).

${ }^{16}$ Alexander Galloway, Protocol. How Control Exists After Decentralization, Cambridge, MIT Press, 2004.
} 
these subjects' freedom to comply or not. A grade, a law, a requisite, a price are all signs the subject must identify and interpret as signs within a certain "signifying semiotics".

By contrast, when I introduce my debit card in an ATM machine, the automated teller does indeed send me various signs and signals ("press here for fast cash", "enter your code", "take your card"). But these signs are part of an "a-signifying semiotics", because they do not address me as a subject, i.e., as an agent who can choose to respond within an open range of options. All my possible responses are strictly pre-set—pro-grammed—by a protocol-writer. While I can always argue with an obtuse bureaucrat (even if unsuccessfully), I can't argue with an ATM machine, an automated telephone service, or an online registration site. There is nothing to argue about, since my expected behavior is not one of interpretation, but of execution $^{17}$.

Signs are exchanged in these devices, on which semiocapitalism increasingly relies in order to reduce costs and push profits higher. But this exchange of signs is not addressed to us as subjects, but as pre-set machines. We dialogue with them in the same fashion a computer "dialogues" with another computer during automated trading. Within any given situation, stimuli and responses are fully conditioned by each other (if you want sixty dollars from the ATM, all your utterances will have been already pre-scripted for you).

It is within the growing grip of a-signifying semiotics on the current developments of semiocapitalism that the status of gestures should be reassessed. Our subjective experience of gesture rests on its resistance to being reduced to a purely mechanical move. The assembly line atrophies our gestures, not because it leaves the human body inert, but because it imposes physical moves which the subject can hardly experience as "his or her own gestures". In order for a physical movement to be recognized as "my gesture", I need to feel that it comes from me (even as a reaction to an external stimulus): I must be able to imprint my singularity, my "style", on it-indeed my "identity" or my "subjectivity" entirely results from the imposition of a singular style on the various gestures performed by my body.

The same is even more obviously true of our relational gestures (which always express themselves through some form of physical gesture, of course). My social identity is the sum of the gestures I make when interacting with other human subjects (smiles, signs of appeasement, of caring, of sympathy, of aggression, of accusation, of forgiving, etc.). A most important political struggle, at all levels of our lives, consist therefore in asserting, defending, and reclaiming the status of our human and subjective relational gestures against the generalization of mechanical a-signifying semiotics imposed by the race to profit that is driving semiocapitalism.

VI. The oppressive power of the protocols set in place by semiocapitalism rests on our digital illiteracy, i.e., on our inability to read and rewrite the software which commands our interface with hardware. The second reason why computerized protocols mark a new stage in the development of semiocapitalism will bring us back to the issue of reading (and writing). Computers impose a-signifying semiotics upon us only because most of us are illiterate: if only we could enter into the programming language of the software, as it designs our interface with the hardware, the functioning semiotics would no longer appear to

\footnotetext{
${ }^{17}$ See Maurizio Lazzarato, La fabrique de l'homme endetté. Essai sur la condition néolibérale (Paris: Editions Amsterdam, 2011) 106-120.
} 
us as "a-signifying". Two distinct but closely related problems should be addressed on this issue.

First, in contrast with the signifying semiotics used within traditional human interactions, the a-signifying semiotics used in our interface with machines leave no room for interpretation. As we all know, there is no margin of error when you type a command or when you enter data into a computerized protocol. Either the string of characters corresponds to the protocol's expectations or it does not, depending on what has been initially programmed in the machine. A human reader will spontaneously correct a typo when she reads a book; a computer will either not notice it and include the error in the data as if it were accurate, or completely block the protocol, if it cannot recognize the string of characters among the valid possibilities pre-programmed into the software. Even if our intelligent machines execute amazingly complex computations, they often look irritatingly "dumb" when, for instance, they block a process as simple as ordering a product online, only because my (French) zip code is not recognized among the list of valid (American) zip codes written in the software. To put it in simplistic but traditional language, human communication is "free" (to err and correct itself), while machines work in a strictly deterministic (and "mechanical") fashion.

Second, contrary to a common misconception, the mechanical (and dumb) reaction of the machines is no more inherent in their "nature" than "freedom" is inherent in ours. While our first experiences with computers frequently led us to face a wall of inflexible dumbness (as illustrated by the zip code example), we are increasingly granted "intelligent" machines which can double-guess our desires, correct our mistakes when we enter a typo, and guide our searches on the internet by providing strings of characters similar to those most frequently entered. Over the last decades, thanks to countless breakthroughs in the design of the Human Computer Interface (HCI), we have witnessed (and benefitted from) an amazing softening of the way in which, through a further elaboration of the software, hardware responds to our demands ${ }^{18}$.

Just as our "free" behavior may result from a unique entanglement of multifarious determinations, similarly, this softening of the software results from a certain margin of interpretation which can be written in the machines, so that they behave in a less dumb and apparently more intelligent fashion. The latest research on the neural processes involved in the activity of reading reveals "a massively parallel system where all neurons compute simultaneously" within a "pandemonium" model relying on the brute quantitative force of mechanical computing rather than on the traditional view of the subtle finesse specific to human intelligence ${ }^{19}$.

However, while neurobiologists try their best to understand the (mechanical) way in which our (dumb) neurons manage to process something as maddeningly complex as the activity of reading, most human readers have not yet seriously tried to understand (and control) the ways in which our computing machines process our social interactions. Very few of us have ever attempted to look under the hood of the protocols which structure our communication with machines and, through these machines, with our fellow-subjects. Most of

\footnotetext{
${ }^{18}$ For a powerful interpretation of the development of the new media in terms of a relation between interface and database, see Lev Manovich, The Language of New Media (Cambridge MA: MIT Press, 2001).

${ }^{19}$ See Stanislas Dehaene, Reading in the Brain. The New Science of How we Read (New York: Penguin, 2009), 43-44.
} 
us humans - and specially "humanists" — seem to be content with our digital illiteracy. We blame (and despise) computing machines and protocols for their dumbness, but we don't give ourselves the intellectual and practical tools to intervene in the making, correcting, restructuring, hijacking - i.e., "hacking" — of these protocols. Hackers and hacktivists may be the true Humanists and cultural critics of our age.

In other words, there is no ontological abyss between "a-signifying" and "signifying" semiotics (deterministic vs. free, machine vs. human, meaningless vs. meaningful). There is only a collective cognitive deficiency, which leads most of us to hit our heads against the mechanical nature of the protocols which increasingly guide and structure our lives, only because we are incapable of reading (and rewriting) the software in which such protocols determine our interaction with the hardware - and, further down the line of mediation, with the human subjects connected to these medias.

VII. No less than catalysts of literacy, the humanities should reposition themselves as reflective practices of interpretation. We are enslaved by mechanical protocols mostly because we can't read and (re)write them in a more humane fashion; we need to expand our literacy by understanding how the machines read (and hence format) our desires; we need to reflect upon (and expand) the margins of interpretation which soften the hardware's responses to our needs and queries. If the previous sections of this article have managed to establish such premises, then it should be clear that the disciplines collected under the banner of "the humanities" are positioned to play a crucial role in overcoming the collective cognitive deficiency which threatens our agency in the age of semiocapitalism.

As historians, anthropologists, philosophers, linguists, cinema theorists, or literary scholars, we all share a set of common intellectual features which define us as experts in the softness of interface. Along the lines sketched above to distinguish mechanical reactions from human gestures, it seems fair to say that the humanities explore, map and tread the countless fracture lines which separate recognition from interpretation. If facts could be merely "recognized", in the same mechanical fashion a computer recognizes a preprogrammed set of characters, there would be little need for the humanities. We write books and articles, we talk in class and in colloquia because the data that fuel human lives, at all levels, cannot merely be "read", like barcodes, but need to be "interpreted", pretty much like enigmatic poems. Most often, these data are not simply things or facts, but themselves consist of interpretations: an anthropologist, a historian, a linguist, a film or a literary critic interpret the ways in which human subjects interpret a gesture, an event, a sentence, or an image.

Across their diversity, the humanities at large can therefore be described as reflective practices of interpretation $^{20}$. We certainly have no monopoly on the activity of interpretation, which is practiced by the hard sciences as well as by all of us, as soon as our daily routines slip away from what can be merely recognized within preexisting categories. However, our main and specific task as humanists consists in interpreting our interpretations, i.e., in constructing explicit reflections on the way we humans interpret our world.

In other words: the humanities foster the development of interpretive gestures. Those who denounce cultural studies, deconstruction, literary scholarship and film theory as a waste

\footnotetext{
${ }^{20}$ I tried to develop this thesis in my books L'Avenir des Humanités. Économie de la connaissance ou cultures de l'interprétation? (Paris: La Découverte, 2010) and Lire, interpréter, actualiser. Pourquoi les études littéraires ? (Paris: Editions Amsterdam, 2007).
} 
of time (for the students) and as a waste of resources (for our economy) are not totally wrong when they portray our activities as a form of gesticulation. In front of our students or in front of our colleagues, we perform relational and interpretive moves which probably carry more weight as theatrical "gestures" (addressed to an audience) than as cognitive "actions" (adding data to our knowledge of reality).

Reading and interpreting literature consists of simultaneously immersing oneself in a narrative world and constructing reflective postures towards that narrative world. The posturing is an intrinsic part of the literary experience - and, more broadly, of the humanities at large. Between the university scholar publishing erudite articles in academic journals and the lay reader immersed in a novel during a beach vacation, the difference is more a matter of degree than of essential nature. Both get to be, at some point, immersed in the stories they read; both are led, at some point, to take some critical distance towards what they read, if only in order to tell their partner what the story is about, whether it is worth reading or not, and why.

The history of literary criticism could be succinctly reduced to a succession of different types of interpretive gestures - and gesticulations. Thus literary history postured as a positivist reinscribing of the literary work within the socio-historical context of its emergence; hermeneutics posed, in front of a mirror and in slow motion, as a projective extraction of meaning out of a given textual material; structuralist poetics proudly displayed its virtuosity in reducing multifarious textual expressions to a mere combination within a limited set of abstract categories; deconstruction gesticulated, again and again, to the same basic trick of showing how any claim to truth ends up betraying some obscure awareness of its own impossibility; cultural studies performed the same gesture of dipping the text in the developing bath of class, race, and gender in order to reveal its biases and/or emancipatory potentials.

More recently, the "théorie des textes possibles", initiated by and around Michel Charles and Marc Escola, invites us to perform a gesture of amplification, allowing the critic to actualize an episode that remains only virtual in the published text ${ }^{21}$. Christophe Hanna and his accomplices, reunited around the publishing house Questions théoriques, call for gestures which tend to short-circuit the distance inherent in interpretive (and aesthetic) positioning: literary works, just like ATMs, trigger functional responses, largely based on execution and asignifying semiotics, as much as they trigger hermeneutical forms of reflective understanding $^{22}$. In Uses of Literature, Rita Felski has gathered these many forms of (interpretative and post-interpretive) postures under the four basic categories of recognition, enchantment, knowledge and shock: recognition allows us to identify with an alien subjectivity through an immersive enchantment enclosing us "in a bubble of absorbed attention", leaving us "sucked in, swept up, spirited away", "mesmerized, hypnotized, possessed", "sapping [our] sense of autonomy and self-control" (similarly to our postinterpretive interface with a-signifying semiotics) — which in its turn leads to the alternate effects of shock, received from being thrown into an alien environment, and knowledge,

\footnotetext{
${ }^{21}$ Marc Escola (dir.), Théorie des textes possibles (CRIN 57; Amsterdam: Rodopi, 2012). On the status of the virtual in literature, see also Arturo Mazzarella, La grande rete della scrittura. La letteratura dopo la rivoluzione digitale (Torino: Bollati Boringhieri, 2008).

${ }^{22}$ Christophe Hanna, Nos dispositifs poétiques (Paris: Questions théoriques, 2010).
} 
brought by the possibility of "knowing something of what it feels like to be inside a particular habitus" 23 .

VIII. The humanities are designed to work towards the softening of our protocols of interaction. All these different types of gestures displayed within the literary field over the past hundred years can probably be observed, with some alterations, in the many disciplines gathered under the banner of the humanities. Taken together, these interpretive gestures practiced and promoted by the humanities have the capacity to act jointly towards the softening of our protocols. This softening effect can be located on at least three levels.

1) The very nature of interpretation makes it a "soft" activity, whether its object is a literary text, a picture, a concept, a historical event, a ritual, or a collected set of scientific data. Interpreting calls for much more complex gestures than reading. The activity of reading - which, of course, almost never takes place in its pure form and always involve some amount of interpretation - can in principle be reduced to the "hard" (i.e., purely mechanical) sorting out of data according to preprogrammed categories and protocols, as illustrated in the most basic case by a scanner reading a barcode. By contrast, as Richard Shusterman has powerfully shown ${ }^{24}$, we only launch a process of interpretation when preexisting categories fail to give us a grip on what is at hand. We have recourse to the necessary softness of interpretation when our hardened protocols prove unable to manage the constant novelty springing up in our experience. In other words, interpretation is all about leeway, i.e., about using or generating a margin of movement within the constraints of predefined procedures.

$\left.2^{\circ}\right)$ In multiplying - often artificially-the opportunities to practice reflective interpretation, the humanities can be considered as a form of intellectual gymnastics, flexing the adaptive muscles on which we rely to overcome the shortcomings of pre-established protocols. It is the heterogeneity of the interpretive gestures we are led to accomplish, when faced with various types of texts, pictures, or narratives, which helps us the most in flexing these muscles. Rather than developing one favorite method of interpretation (literary history, hermeneutics, structuralism, deconstruction, cultural studies, and the like) - as dissertation directors often advised their doctoral students to do-we should make it a point to combine various and potentially heterogeneous approaches, since the invention of unchartered combinations and inflections among preexisting protocols defines the core activity and values of the humanities.

3) Reading and interpreting literature (or films, or arguments, or myths, or rituals, or historical trends) also tends to soften our interactive procedures because its transmission relies on the imitative dynamics of exemplarity, rather than on programming by command. As Timothy Hampton has shown in a book devoted to the Renaissance, exemplarity has always played a crucial role in our relation to literature ${ }^{25}$. Italian critic Daniele Giglioli recently suggested that literary studies should re-invent themselves around the dynamics of gestural exemplarity: "Critique and theory should evolve from interpretation to exemplification, they should consider themselves not so much as thought or communication than as gestures, as

\footnotetext{
${ }^{23}$ Rita Felski, Uses of Literature (Oxford : Blackwell, 2008), 54 and 92.

${ }^{24}$ On this definition of interpretation, see Richard Shusterman, Pragmatist Aesthetics: Living beauty, Rethinking Art (Oxford: Blackwell, 1992)

${ }^{25}$ Timothy Hampton, Writing from History. The Rhetoric of Exemplarity in Renaissance Literature (Ithaca: Cornell University Press, 1990).
} 
performances, as events, as constitutive processes which provide themselves with their own rules along the way of their unfolding". When teachers and critics work on a text in front of students or fellow-researchers, "they should claim to those who listen: what matters is not what I say, nor the method I use to say it, but rather the very fact that I manage to speak through the techniques I use. Not: see what is in this text! But: see what can be done by reading, hearing and scrutinizing this text! [...] It is only by moving from enunciation to gesture, from symbol to example, from discourse to action, that theory and critique can still hope to have a future" 26 .

Because we, in the humanities, focus our attention on the processes of interpretation, our work is to be located at the interface between pre-existing programs and emerging expressive needs and desires. This work on the interface requires a softness of approach which goes against both the rigidity of top-down command (as it is imposed in administration) and the systematicity required from the "hard" sciences. We therefore must claim gestures as our main mode of performance, since human gestures, while obviously shaped by previous training and structured by environmental constraints, display an exemplary capacity to transcend their programming.

\section{Towards a Political Ecology of Gestures, or Literature Everyware}

IX. Through their softening agency, the Humanities provide a crucial set of sites and tools in order to promote the humanity of gestures against the pre-formatting of protocols. Let me survey the rather sinuous and rushed trajectory of my argument so far. I started by emphasizing the "affective" nature of our reading experience: in triggering emotional reactions to the fictional situations in which we immerse ourselves, reading contributes to shaping our relational gestures, which are imported and adapted from fictional worlds and made part of our actual agency. I then suggested that reading novels (as well as, later, watching movies and television) played an important role in formatting our modern gestures, desires, and subjectivity along the lines needed by capitalism in order to rely on the adaptive collaboration of individual agents, as these agents are constantly expected to espouse transindividual trends while constantly being called to invent more livable ways to adjust their relational movements. The inculcation of relational gestures through reading (and later through the expansion of audiovisual narratives) is to be seen as the true manufacture of homo oeconomicus, insofar as this awkward species cannot operate as a merely self-interested factor of production endowed with "rational expectations" (as neoliberal economic "science" would have us believe), but must sustain his productive work on a much deeper and wider affective relational ground.

I then staged a major tension between gestures and protocols within the development of a later phase of modernity, here called semiocapitalism with reference to Franco Berardi's analyses. Through the processes of industrialization, state bureaucracy, and now

\footnotetext{
${ }^{26}$ Daniele Giglioli, "Tre cerchi. Critica e teoria". Il verri, 45 (2011) : 26. My translation. A French translation is available in La Revue des livres 6, July 2012, 50-65.
} 
computerization, our societies have pushed further than ever before the programming of our behavior, i.e., the tendency to "pre-write" and pre-format our relational movements. Within this multi-secular history, programming has passed through various phases, which Foucault, Kittler, Debord, Baudrillard, Deleuze and Guattari, and Hardt and Negri have helped summarize as consisting of roughly three stages (the logic of the earlier stage never fully disappears, but it is mainly reconfigured within the later stage). In the age of Sovereignty, a rather weak central power attempted to impose minimal commands top-down, along centralized networks; in the age of Discipline, a multiplicity of more or less loosely articulated institutions attempted to train individuals in order to program rigid behaviors within decentralized networks; in our age of Control, "distributed networks" rely on each individual's capacity to adapt to the requirements, pressures, and evolutions of the collaborative grid within the constraints specified by the various protocols which format our diverse levels of interaction.

As Alexander Galloway often stresses in his book, the main question, in the age of Control, is "not that protocol is bad, but that protocol is dangerous": "for all its faults, protocological control is still an improvement over other forms of social control" 27 . I have characterized this danger by opposing programs to gestures. Protocols have always existed, in the form of rituals, judicial procedures, administrative requirements, rules of engagement, managerial practices. It is the mechanization of protocols through our recent information and communication technologies which raises new dangers, along with amazing new possibilities.

The performative nature of our gestures must be strongly asserted, defended, practiced, and cultivated in order to counterbalance the reduction of human agency to mere execution brought by the inescapable mechanization of our interactions. By performative, I mean first that gestures are theatrical performances, as opposed to actions: they are meant to be seen, they are addressed to an audience (even if only a virtual one), they always include a dimension of make-believe, which is not necessarily deceptive, since even when we speak the truth, we do so in an attempt to make our audience believe it is the truth.

By performative, I also mean that the specific power of gestures relies on their status as athletic performance: a sportsman, a musician, a dancer - in fact any "performer" - knows that her most rewarding and most acclaimed gestures transcend her previous training as well as the protocols she had set in place in order to boost her ability. Any successful gesture includes a dimension of improvisation which decisively exceeds its original programming.

Finally, as a consequence of this improvisational excess, by performative, I mean the ontological productivity of human gestures, insofar as, by the virtue of their exemplarity, they sometimes precipitate the actualization of social movements which had remained only virtual. Like performative speech acts, gestures are a way for us to "do real things" with mere words, poses, postures, gesticulations, plays. A gesture of defiance may trigger a revolution; a gesture of threat may prevent an attack; a gesture of good will may diffuse a conflict. Here again, these three connotations of the performative nature of gestures converge in their exemplarity: an exemplary gesture inspires imitators and followers by displaying in full view an unbelievable feat of unimaginable agency.

\footnotetext{
${ }^{27}$ Galloway, Protocol, 16-17.
} 
I hope the previous pages, in spite of their precipitate nature, have at least hinted at how the reading of literature is intimately tied to the modern history of gestures. Apart from the inculcation of relational gestures, reading literature leads us to enjoy the exemplary power and virtuosity of the expressive gestures performed by the writer. As students, teachers, scholars, it stimulates us to pursue these expressive feats by constructing our own interpretive gestures, along the lines sketched in the texts.

Literary studies, therefore - and, more broadly, the humanities at large, insofar as we conceive them as reflective practices of interpretation-appear as a crucial site for our societies to refine the interface through which we interact and collaborate. What is at stake in our fields of study is the obstinate resistance of human gestures to any attempt to subsume and entrap them in any form of rigid programming protocol. Why this resistance is particularly important in the age of semiocapitalism and what it means in terms of the reconfiguration of our discipline will be addressed in my concluding point.

$X$. Considered within the broader scope of media archaeology, literature is everyware. The contradictory tension between the "hard" and the "soft" permeates all of our current debates. Whether on the geopolitical field (hard power of troops sent abroad vs. soft power of TV series exported), in the management of crime (harshness of punishment vs. flexibility of rehabilitation), or in the evaluation of research (individually quantified impact index vs. collective percolation of minor initiatives), the softening power of the Humanities should be understood within a basic opposition of values, much wider than the traditional divide, famously sketched by CP Snow in his 1959 talk, between "the two cultures" of hard sciences vs. soft humanities - if only because good science necessarily has to soften itself when it goes through a paradigm shift, before hardening again when its new protocols reach satisfactory efficiency.

What is at stake in this opposition is a broader anthropological evolution which relies ever more massively on "show business" (aka Debord's spectacle, Baudrillard's simulation, or McLuhan's media) in order to coordinate globally our molecular behaviors: the businesswhich-organizes-what-is-shown conditions what we do. It does so softly, but ever more intimately and intensely. This increasingly crucial importance of show business is what makes gestures more important than ever, since, as I have stressed above, a gesture includes at least some awareness of its being displayed to the attention of an audience. This is why Franco Berardi's semiocapitalism appears the most accurate way of naming our current form of social and global organization. Through the development of, first, the printing press, then film and television, and now the internet and the world wide web, the capitalist logic of development relies increasingly on an ever larger and ever more multi-leveled set of "signs" (semeia) - whether through a-signifying or signifying semiotics, through texts, sounds, pictures and videos, but also through narratives, arguments, and scientific models. All of these signs, in their multifarious diversity, appear within show business in the form of gestures: while their constitution as well as their communication obviously rest on (sometimes rigidly constrained) protocols, they manage to speak to us only insofar as we identify them as human gestures.

As Matteo Pasquinelli recently argued, show business and its signs should not simply be equated with the mediasphere, conceived as something external to our subjectivity, floating "out there" in the air waves or through the cables of the internet. Show business constitutes a 
neurospace which "should not be considered an autonomous media sphere, but a continuum between inner and outer landscapes, between the psychological and libidinal life of any physical form and object" 28 . Hence my insistence on situating reading within an economy of affects, i.e, at the place of interaction between exterior affections and interior emotions: the interface the humanities can help us to soften and humanize is the one that connectsworldwide, through the tip of our fingers, the drum of our ears, and the pupil of our eyes - our centralized network of nerves with the distributed network of the various machines in which we have progressively exteriorized our chains of operations, both physical and mental.

The new scope of the humanities, therefore, can no longer be limited to "literary" texts, or "philosophy", or "the Arts". We may well want to focus our attention occasionally on literary texts, but what we are studying and attempting to understand — and soften—is, much more broadly and ambitiously, the way human gestures have interacted with communicating machines for several hundred years, within the general scope already provided by "media archaeology" 29 . To hijack a neologism referring to the countless miniaturized forms of hardware which already permeate our living environment (from smartphones to sensors and RFID tags $)^{30}$, reading and interpreting the signs provided in literary texts leads us to see that literature is everyware. What we work on is the ubiquitous "wetware" which flows in the distributed networks of the hardware through the protocols of the software.

In order to defend "literature" as a form of attention to the gestural dimension of any expressive move, we not only need to realize it is everyware. We also need to develop a political ecology of gestures. Against a political economy which, over the past three decades at least, has constantly eroded our interpretive spaces, in the name of market competition, consumerist growth, and individualistic property rights, we need to reclaim the anthropological centrality of the interpretive gesture. Humans never merely read data or execute commands: they interpret signs. The art of interpretation-historically cultivated by the humanities, after having been the monopoly of religions during countless centuriesshould be recognized, and funded, as the most vital endeavor of the human adventure.

XI. A political ecology of gestures calls for three literary human rights: the rights to opacity, to equivocation, to reformulation. To conclude this call for a political ecology of gestures, I will delineate three eminently literary human rights which show the deep continuity that links our practices as literary scholars with much broader political, societal, and anthropological claims.

Edouard Glissant repeated on numerous occasions that the preservation of linguistic and cultural diversity depended upon recognizing for everyone a right to opacity: "a general consent to particular opacities is the simplest equivalent to non-barbarianism"31. It belongs to

\footnotetext{
${ }^{28}$ Matteo Pasquinelli, Animal Spirits: A Bestiary of the Commons (Rotterdam: NAi Publishers/Institute of Network Cultures, 2008), 162.

${ }^{29}$ See Jussi Parikka, What Is Media Archaeology? (Cambridge: Polity Press, 2012) and Ekki Huhtamo et Jussi Parikka, Media Archaeology. Approaches, Applications, Implications (Berkeley: University of California Press, 2011).

${ }^{30}$ See Adam Greenfield, Everyware: The Dawning Age of Ubiquitous Computing (Berkeley: New Riders, 2006).

31 «Le consentement général aux opacités particulières est le plus simple équivalent de la non-barbarie » Édouard Glissant, Poétique de la Relation, Paris, Gallimard, 1990, p. 209 (my translation). For a remarkable synthetic presentation of Edouard Glissant's thought, see Alain Ménil, Les voies de la créolisation. Essai sur Édouard Glissant, Grenoble, De l'incidence, 2011.
} 
the very nature of protocols to homogenize practices and to "promote standardization in order to enable openness" ${ }^{\prime 32}$. By requiring the programming and the entering of data to be fully explicit in order to fit the requirements of the hardware, computerization imposes transparency. Insofar as they transcend preliminary training and routines, human gestures, on the contrary, constantly maintain a reserve of opacity. The same reserve of opacity is the source of the endless succession of ever changing interpretations literary scholars have elaborated when reading canonical works. In claris non fit interpretatio: there can be no interpretation without some sort of opacity. Similarly: there can be no truly human gesture with an expectation of full transparency.

Brazilian anthropologist Eduardo Viveiros de Castro stresses how much intra- as well as inter-cultural communication relies on the virtue of equivocation, which "is not just one among other possible pathologies that threaten communication", but "a properly transcendental category of anthropology, a constitutive dimension of the discipline's project of cultural translation". Correlative to a right to opacity, a resistance against the standardization and univocality brought about by protocols calls for a right to equivocation. Here again, this right appears as a necessary implication of the interpretive activity. Were there no double meaning - differing meanings that are equally acceptable when considered from different points of view-there would be no literary studies, nor anthropology. The humanities are needed in order to unfold the perspectival differences which are implicated in such equivocation. This is what fuels their endless work of interpretation and translation: "to translate is to situate oneself in the space of the equivocation and to dwell there. It is not to unmake the equivocation (since this would be to suppose it never existed in the first place)". To interpret, or to translate, "is to emphasize or potentialize the equivocation, that is, to open and widen the space imagined not to exist between the conceptual languages in contact, a space that the equivocation precisely concealed. The equivocation is not that which impedes the relation, but that which founds and impels it: a difference in perspective. To translate is to presume that an equivocation always exists; it is to communicate by differences, instead of silencing the Other by presuming a univocality - the essential similarity — between what the Other and We are saying." 33

Both opacity and equivocation constitute the reserve of meaning out of which human history has drawn its dynamics of renewal and development. Both converge in claiming a third right, which lies at the very foundation of the work accomplished by the humanities: a right to reformulation. Protocols confront us with "forms" — not aesthetic forms but computerized forms, requiring us to fill in pre-parametered blanks. Faced with such forms, we have no margin of freedom to rephrase the questions asked or the responses to be given. Because the programming languages used in writing software do not express meaning, but trigger the execution of operations, they are designed to short-circuit interpretation.

Once again, literature and the humanities provide a model for the articulation of a broader political ecology of gestures. Reading and interpreting literature can be seen as a ceaseless exercise in reformulation: no two readers have read, summarized, described, analyzed, perceived the same work in exactly the same fashion. Whether interpretive, artistic

\footnotetext{
${ }^{32}$ Galloway, Protocol, 142.

${ }^{33}$ Eduardo Viveiros de Castro, "Perspectival Anthropology and the Method of Controlled Equivocation", Tipití: Journal of the Society for the Anthropology of Lowland South America, Vol. 2-1 (2004), 10.
} 
or athletic, human gestures are always repeated, while never the same: they can be performed over and over again, because there are driven by an endless aspiration towards better reformulation.

As stated above, it would be overly simplistic and deceptive to consider computing machines as merely antagonistic to human gestures: our relational gestures are multiplied, diversified, augmented, and enriched by the availability of new communicating devices, along with their protocols. However, a political ecology of gestures requires us to maintain and promote the constitution of protected interpretive spaces, within which opacity, equivocation, and reformulation can play their role in the refinement of our life worlds. The practice of reading literature may provide the blueprint for the next generation of human rights in the age of semiocapitalism. 